
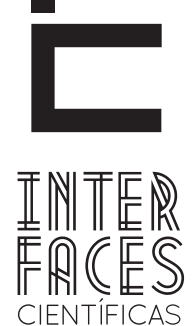

EXATAS E TECNOLÓGICAS

ISSN IMPRESSO - 2359-4934

\title{
WEB DESIGN RESPONSIVO: CAMINHOS PARA UM SITE ADAPTÁVEL
}

Fabiano dos Santos França ${ }^{1}$

\section{RESUMO}

0 presente artigo tem por objetivo discutir a importância de utilizar o web design responsivo na construção de sites, a fim de garantir um site adaptável, agradável, sem abrir mão da usabilidade para os usuários de dispositivos moveis. Inicialmente, caracterizamos o que vêm a ser a web responsiva e seu nascimento. Em seguida, apresentamos a tríade para construir um site adaptável a qualquer tamanho de tela. Portanto, conhecer a tríade (layout fluídos, media queries e imagens responsivas) para construção de um site responsivo é importante para os web designs, sendo que se aprofundar mais neste assunto contribuirá no desenvolvimento de um site responsivo mais estruturado, seguro e expansível.

\section{PALAVRAS-CHAVE}

Layout fluído. Design responsivo. Media queries. 


\section{ABSTRACT}

This article aims to discuss the importance of using responsive web design on building sites in order to ensure an adaptable site, pleasant, without compromising the usability for users of mobile devices. Initially characterized the coming to be responsive web and birth. The following are the triad to build an adaptive site at any screen size. Therefore, knowing the triad (fluid layout, media, queries and responsive images) to build a responsive site is important for web design, and go deeper in this matter will help in developing a more structured site responsive, secure and scalable.

\section{KEYWORDS}

Fluid Layout. Responsive Design. Media Queries.

\section{RESUMEN}

Este artículo tiene como objetivo discutir la importancia de utilizar el diseño web sensible en las obras de construcción con el fin de asegurar un sitio de adaptación, agradable, sin comprometer la facilidad de uso para los usuarios de dispositivos móviles. Inicialmente, caracterizamos el llegando a ser páginas web sensibles y el nacimiento. A continuación, presentamos la tríada para construir un sitio de adaptación a cualquier tamaño de pantalla. Por lo tanto, conociendo la tríada (fluidos de diseño, las consultas de los me- dios de comunicación y las imágenes sensibles) para construir un sitio sensible es importante para el diseño web, y profundizar en este asunto ayudará en el desarrollo de un sitio más estructurado de respuesta, segura y escalable.

\section{PALABRAS CLAVE}

Fluido Diseño. Diseño de respuesta. consultas de los medios de comunicación. 


\section{INTRODUCÃ̃O}

Se olharmos para a história, o ser humano assim como as coisas a sua volta, está em constante evolução. Mensagens que eram passadas por bilhetes com o passar do tempo caíram em desuso, sendo substituídos por cartas, fax, correio eletrônico, SMS e outros meios eletrônicos que existem hoje em dia.

Assim também aconteceu com os dispositivos eletrônicos com acesso a internet. Tudo evoluiu, trazendo melhorias para esses dispositivos. Temos televisões com resolução $4 \mathrm{k}$ e aparelhos celulares com tela de 320px. Como garantir que seu site atinja ao menos $90 \%$ dos dispositivos atuais? A resposta é: Utilizando o Web Design Responsivo.

\begin{abstract}
Uma coisa importante para ter em mente são as diferenças na usabilidade entre dispositivos móveis e Desktops. 0 papa da usabilidade, Jakob Nilsen, fala que as diferenças são tão brutais que precisamos de design diferente para atacar esses públicos. Isso pode ser feito de várias maneiras: sites diferentes pra mobile e Desktop; servidor otimizando a página; ou design responsivo e adaptação do design no cliente. (LOPES, 2013, p. 10).
\end{abstract}

Dentre as várias maneiras citadas por Lopes (2013), uma que vem ganhando espaço na web são os sites responsivos, pois estes se adaptam a todos os tamanhos de tela independente do dispositivo que esteja sendo utilizado. Entre os extremos, desktop e dispositivo móvel (celular), temos uma vasta lista de dispositivos eletrônicos que tem características de ambos. Um simples exemplo que deixa claro esta questão é se fizermos um site diferente para mobile. Como seria apresentado um site em um tablet de tela de 10 polegadas?

Assim, neste artigo discutimos a importância de utilizar o web design responsivo na construção de sites, a fim de garantir um site adaptável, agradável, sem abrir mão da usabilidade para os usuários de dispositivos moveis. Inicialmente, caracterizamos o que vem a ser a web responsiva e seu nascimento. Em seguida, apresentamos a tríade para construir um site adaptável a qualquer tamanho de tela.

\section{QUEÉ A WEB RESPONSIVA?}

O site UOL (www.uol.om.br) optou por utilizar sites diferentes para mobile e desktop. Ao abri-lo em um navegador que esteja instalado em um sistema operacional desktop, veremos a versão desktop do site. Se abrirmos em um navegador com sistema operacional mobile (android, IOS, WindowsPhone) este abrirá uma outra versão com uma URL diferente da versão desktop. Como apresentados nas figuras a seguir.

Figura 1 - Versão Desktop

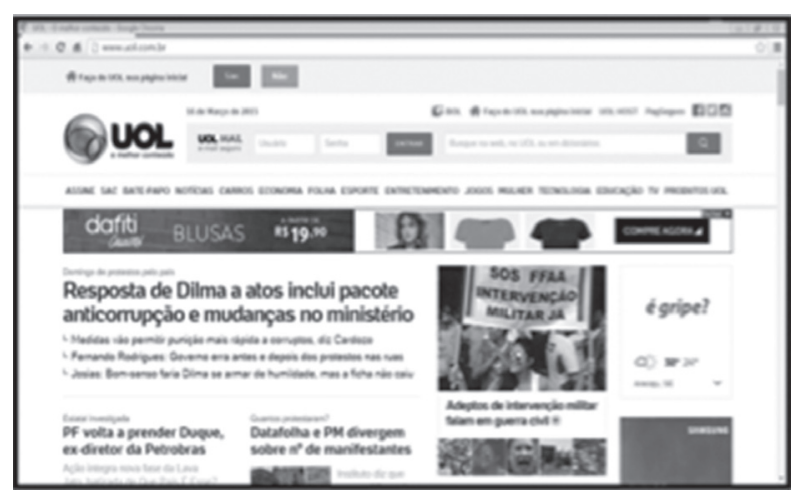

Fonte: www.uol.com.br 
Figura 2 - Versão Mobile

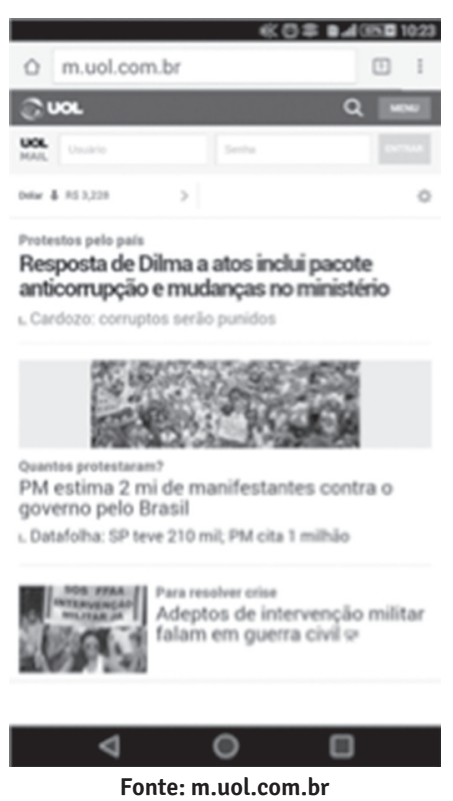

Um dos problemas que facilmente é detectado na versão desktop deste site são as medidas fixas (pixels). Se redimensionarmos a janela do navegador, perderemos parte do site, obrigando ao usuário visualizar o site sempre em tela cheia. Já na versão mobile, temos um problema ainda maior. 0 que é definido por mobile? Apenas o dispositivo celular (smarthphone)? Se abrirmos o site em um computador híbrido (computador que vira tablete), a versão do site da uol seria a mobile. Mas o tamanho da tela é como um computador desktop. Ou seja, iria abrir a versão mobile dentro de uma "tela desktop", fazendo com que os elementos do site se expandissem, deixando um visual nada agradável. Nasce perante estes problemas a pergunta: 0 que posso caracterizar como mobile?

\section{1 CARACTERIZACÃO DE MOBILE}

Caracterizar mobile é complicado! Há características que ambos os dispositivos têm (desktop e mobile), como touch, rede móvel, portabilidade etc. Pode pa- recer um exagero, mas o que temos são os extremos, desktop e mobile. E entre esses extremos uma vasta lista de dispositivos que herdam características de ambas as partes. Para Lopes $(2013$, p. 1) "não existe uma Web mobile. Existe a Web, que a gente acessa tanto do computador quanto do celular ou tablete. É o HTML, CSS e Java Script que rodam nos navegadores independente do dispositivo".

Para alcançar todos os dispositivos precisamos ter a visão de projetar sites responsivos, pois esse é o futuro da web. É fato que uma característica constante da web é a flexibilidade e temos que adaptar nossos sites a essa característica. Segundo Zemel (2013, p. 10), desenvolver para a web única:

\begin{abstract}
Não se trata de uma "moda" ou um hype da internet; não se trata de algo que chegou, vai angariar alguns fãs e sumir na próxima estação. O Web Design Responsivo é uma nova forma de pensar a web e, dentro de pouco tempo, será tão vital e importante aos desenvolvedores e à experiência do usuário quanto o próprio HTML ou o CSS.
\end{abstract}

\subsection{UM NOVO OLHAR - NASCIMENTO DA WEB RESPONSIVO}

Fica claro que projetar sites para o design responsivo não é mais um diferencial, passou a ser obrigatoriedade se quisermos alcançar todos os usuários. Acredite! Hoje tudo se encaminha para o responsivo, engenheiros de varias áreas e indústrias estão desenvolvendo projetos de produtos responsivos. Vidro inteligente que se torna opaco, uma vez que tenha pessoas no quarto; Superfícies que reagem a voz com a música; Ambientes que podem reformar-se para melhor atender os seus ocupantes; são exemplos de projetos que foram desenvolvidos para serem responsivos.

Segundo Zemel (2013) um dos escritores do AList Apart, Ethan Marcotte, publicou um artigo intitulado Responsive Web Desgin que mudou a forma como se faz design para web. No decorrer do artigo, Ethan explica seus conceitos e sugestões (usando tecnologia 
que já era existente à época de sua publicação) para que as páginas fossem projetadas, usando o que ele chamou de web design responsivo.

Ethan possibilitou uma nova era em que sites respondem, a quaisquer dispositivo/resolução e, devido a uma série de características técnicas bem específicas, é bem apresentado em qualquer um deles (ZEMEL, 2013).

\section{TRÍADE PARA WEB DESIGN REPONSIVO}

Segundo Marcotte (2011) para desenvolver sites adaptáveis a qualquer tamanho de tela, precisará de três ingredientes: 1. Layout baseado em grid flexível; 2. Imagens e Medias Flexíveis, e 3. Media quereis, um módulo a partir da especificação CSS3.

\subsection{LAYOUT FLUÍDO}

Segundo Lopes (2013) a grande estrela de um web design responsivo é o layout fluído. Isso quer dizer não usar medidas fixas como pixels (ou pontos, centímetros, milímetros etc.) pra programar o design. Não dá mais pra copiar as medidas no Photoshop da imagem estática que o designer criou com o layout do site. Layout fluído é usar medidas flexíveis e é tão velho quanto o HTML em si.

A exemplo do site uol, trabalhar com medidas fixas vai contra tudo que a filosofia de uma web adaptável prega. Pois ao redimensionarmos a janela do navegador os componentes do site não se adaptam. Trabalhar com layout fluidos é trabalhar com medidas flexíveis. Há várias, mas as que mais se destacam no mercado é a porcentagem, em erem.

\section{2 PORCENTAGEM}

Ao trabalharmos com porcentagem para definir 0 layout de um site, devemos olhar de forma diferente. No exemplo abaixo temos um layout que foi dividido em porcentagem, onde o body (pai) tem 100\% de largura (width) e seus filhos 20\%, 60\% e $20 \%$ respectivamente. 0 total da largura dos filhos é igual ao do pai. Então se tivéssemos que dividir o layout em três grids iguais, dividiria $100 \%$ por três. Cada grid ficaria com $33,33 \%$ de largura.

Agora, se tivéssemos que acrescentar mais duas <section> na grid central, no exemplo abaixo, qual valor em porcentagens cada section receberia? Para encontrar o valor das section divida 100\% (do pai, div) por dois. Cada section receberia 50\% como valor de largura.

Figura 3 - Exemplo grid porcentagem

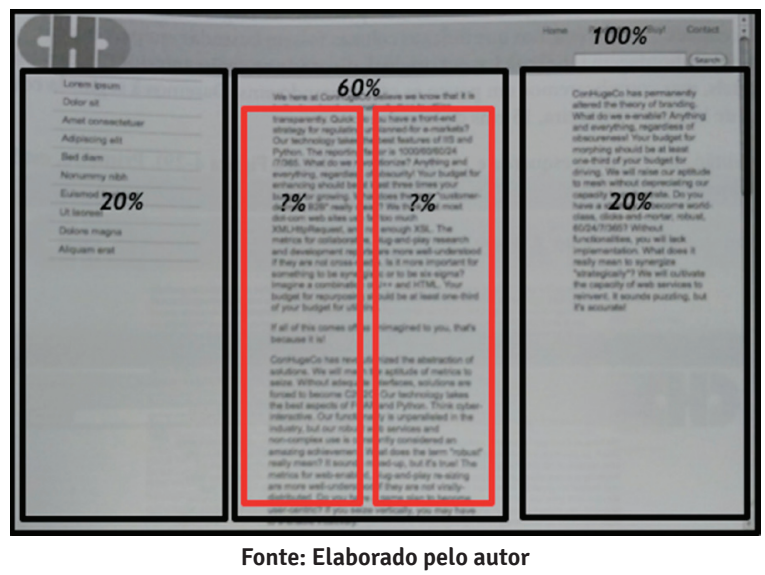

\subsection{EMEREM}

As medidas $\boldsymbol{e m}$ e rem são geralmente utilizadas para definir os valores do font-size, margin e padding. Mas também podem ser utilizadas para definir largura e altura de outros componentes. Essas medidas equivalem ao tamanho de font-size do body (por padrão é 16px), então um equivale a $16 p x$.

A diferença entre as duas é que a medida $\boldsymbol{e m}$ tem herança em cascata. Um elemento definido como em precisará verificar qual o font-size de seu elemento pai, para depois do cálculo, definir seu próprio valor. 
Figura 4 - Exemplo grid em e rem

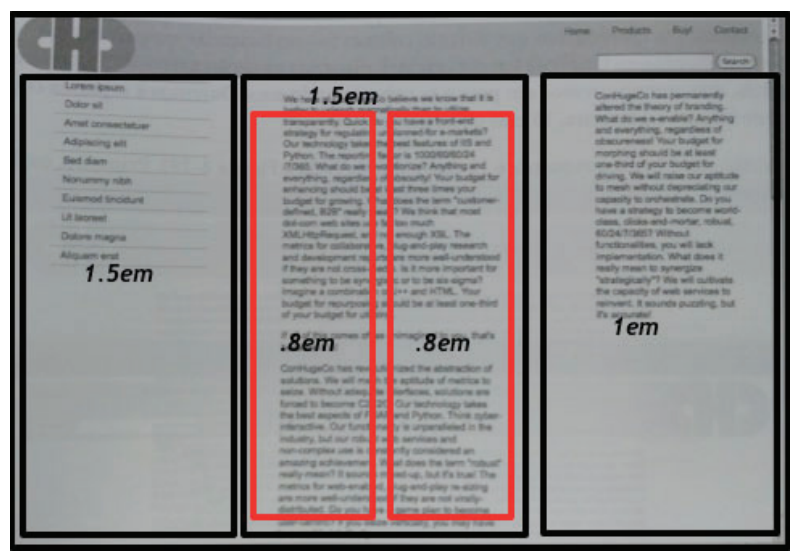

Fonte: Elaborado pelo autor

No exemplo acima, não foi definido nenhum valor para o body, logo o tamanho do font-size é $16 \mathrm{px}$. 0 blocos que estão definidos como $8 \mathbf{e m}$ tem como pai um elemento com font-size $24 \mathrm{px}$.

$$
\begin{aligned}
& 16 p x * 1.5 e m[24 p x ; \\
& 16 p x * 1 e m[16 p x ; \\
& 24 p x * .8 e m \text { X } 19 p x ;
\end{aligned}
$$

Se o mesmo exemplo estivesse definido com medidas $\mathbf{r e m}$, a referência de todos os elementos independente de sua hierarquia, seria o font-size do body.

$$
\begin{aligned}
& 16 \mathrm{px} * 1.5 \mathrm{em} \times 24 \mathrm{px} ; \\
& 16 \mathrm{px} \text { * 1em } \mathrm{e} \text { 16px; } \\
& 16 p x \text { * .8em }{ }^{2} 19 p x ;
\end{aligned}
$$

Fazer um design totalmente fluído é o único jeito de atacar os múltiplos tamanhos de tela dos vários dispositivos diferentes de hoje. Mas, muitas vezes, deixar a página toda ocupar $100 \%$ do navegador pode não atingir resultados tão interessantes, principalmente nos extremos, em telas muito grandes ou pequenas (LOPES, 2013).

Para restringir o design fluído utilizamos duas propriedades do CSS, o max-widht e o min-width. Ambos irão restringir o redimensionamento do elemento, impedindo que o layout se expanda ou encolha além do valor que foi definido.

\subsection{MEDIA QUERIES}

As medidas flexíveis fazem com que o site adapte-se ao redimensionamento do navegador. Mas há momentos, no redimensionamento da janela do navegador, em que o nosso site não ficar bom. Este momento (ponto) é chamado de breakpoint. Segundo Lopes (2013, p. 62) breakpoint "é o ponto de quebra do nosso layout fluído onde uma reestruturação maior é necessária, [...] para ajustar o design e melhorar a experiência do usuário."

Para ajustar o design nesses pontos precisamos das Media Queries. É com as Media Queries que é possível ocultar, fazer aparecer e reposicionar elementos e interações conforme a resolução atual que esteja sendo usada no momento da visitação do site. Elas surgiram de um recurso já existente no CSS, as Media Types. Mas diferente das Media Types, as Medias Queries não avalia o tipo de dispositivo (screen ou handheld), mas sim a resolução da tela.

Um exemplo clássico do uso de Media Queries é a utilização para o menu responsivo. Onde teremos o menu na versão mobile e outro na versão desktop, sendo definido por media queries em um breakpoint definido.

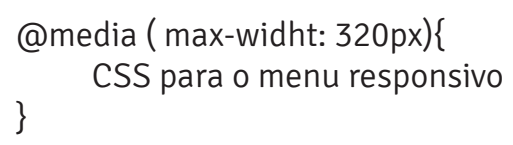

Os valores max-width e min-witdh equivalem respectivamente a menor que ou igual a e maior ou igual. Logo o exemplo acima informa que, quando a tela (portview) for menor que 320px ou igual,devem ser aplicadas as regras CSS que estão dentro deste bloco.

Media Queries é a solução para quando o layout fluido já não é suficiente. Esta trabalha diretamente com o breakpoint. Muitos sites na web trazem bre- 
akpoints definidos, mas cada site requer seu próprio breakpoint. Lopes (2013, p. 93) sugere que você ache seus próprios breakpoints:

- Abra sua página original no navegador;

- Vá redimensionando a janela devagar até o design parecer ruim - se fez mobile-first, abra pequeno e vá aumentando a janela; senão, abra grande e vá diminuindo a janela;

- Quando achar um ponto em que o design quebra, copie o tamanho da janela e crie uma media query com esse valor lá no seu CSS;

- Recarregue a página, veja se as mudanças melhoraram o design, e continue redimensionando pra achar o próximo breakpoint.

- Algumas ferramentas que podem te ajudar nisso:

- O responsive mode do Firefox

(https://developer.mozilla.org/docs/Tools/Responsive_Design_View);

- FitWeird (http://davatron5000.github.com/fitWeird/), um excelente bookmarklet que te dá o tamanho da tela, inclusive em em;

- Meu responsive play (http://sergiolopes.org/ responsive-video-play/).

\section{5 IMAGENS RESPONSIVAS}

Segundo Zemel (2013) nada adiantaria se o conteúdo se adaptasse as mais diferentes resoluções se as imagens (e outros recursos) do site, também, não se adaptassem e não fossem flexíveis, não é verdade? Então, por meio de técnicas variadas, é possível fazer com que as assets (recursos como imagens, vídeos etc.) do site, também, sejam flexíveis para garantir que a experiência do visitante prime pela excelência, independente do dispositivo que esteja usando.

Em alguns casos podemos evitar os pixels em imagens. Em logo marcar, por exemplo, podemos optar por imagens vetoriais, pois se adaptarão ao layout do site responsivo sem perder a qualidade, ou iconfonts. Mas em outros casos não temos como fugir daquelas imagens compostas por pixels.
Para imagens de pixels em um design fluído sem que elas percam qualidade ou desestruturar o layout, existe varias técnicas. Uma delas e a mais simples é utilizar também o max-width e min-width nas imagens, o que chamamos de imagens fluídas. Outra técnica é utilizar as Media Queries para carregar as imagens, dependendo do tamanho da tela. Então, em um viewport menor que 320px carregaria uma imagem com uma qualidade e tamanho menor, para telas maiores que 320 px carregaria uma imagem com outras propriedades que melhor serviria para o site.

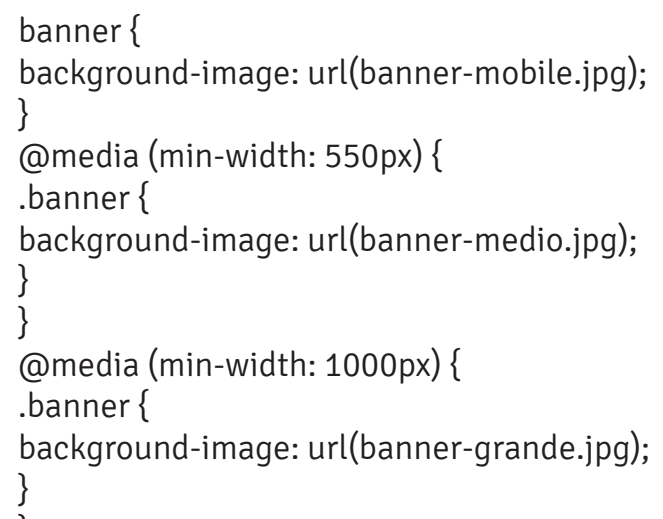

Sendo assim, atingiríamos os três objetivos principais das imagens responsivas: Performance - economizar bytes enviando a imagem do tamanho certo pra cada tela; Qualidade - obter qualidade visual na renderização da imagem de acordo com a resolução; Direção da arte - usar imagens de conteúdos diferentes para adaptar à necessidades de design.

\subsection{COMPRESSIVE IMAGES}

0 grande problema de trabalhar imagens responsivas com Media Queries ou tantas outras soluções encontradas na web é ter que fazer de uma imagem várias versões (tamanho, qualidade). Modificá-las em qualquer editor de fotografia, torna o processo lento e desmotivador. 
E se utilizarmos uma imagem para todos os tamanhos de tela, sem que ela perdesse a qualidade e ainda fosse rápida o bastante? Parece que inventaram uma nova ferramenta para fazer este feito. Mas na verdade é uma técnica que provém de um raciocínio simples. Conforme Lopes (2013, p. 139), imagem compressiva é gerar uma imagem JPEG grande, retina, com o dobro da resolução, mas com qualidade bem baixa. Na hora de exportar a imagem no seu editor favorito, podemos escolher a qualidade - um número de um a cem. A ideia é gerar nossa imagem retina com qualidade 30 , por exemplo, um número bem baixo.

Numa tela normal, não retina, a imagem $2 x$ de qualidade baixa vai ser exibida com metade do tamanho e, para isso, o navegador vai redimensioná-la. Nesse processo, o fato da imagem ter o dobro de pixels vai ajudar a obter uma imagem muito bem definida, equivalente a uma imagem $1 x$ de qualidade alta.

Já numa tela retina, todos os pixels da imagem $2 x$ serão exibidos, sem redimensionamento. Mas a tela tem uma densidade tão alta que os pixels são muito pequenos a olho nu. 0 resultado é que nem notamos a qualidade menor do JPEG. E a imagem fica bem mais nítida que uma imagem $1 x$ tendo seus pixels esticados.

\section{7 VIEWPORT}

Depois de projetar um site com layout fluído, media queries e imagens responsivas, está na hora de colocá-lo no celular e testar. Ops! Algo deu errado. Apesar de aplicar as três técnicas base do web design responsivo, ele não funciona no navegador de um sistema operacional mobile.

Isso acontece porque segundo Lopes (2013, p. 70),
Agora, qual é a mágica para uma página pensada pra um Desktop de 1024px caberna telinha pequena de 320px de um iPhone? A página é redimensionada e aparece menor no celular.

ParaKoch (1990, APUD WROBLEWSKI, 2011, p. 110): "Normalmente a janela de exibição de layout leva uma largura que o fornecedor decidiu ser o ideal para a visualização de sites de desktop [...]". Como solução a Apple introduziu a meta tagviewport, que segundo Marcotte (2011, p. 80) "permite controlar o tamanho da tela (área disponível para exibição do site), e substituir o comportamento padrão. Podendo ditar exatamente quantos pixels a janela do navegador deve ter".

$<$ metaname="viewport" content="width=device-width, initial-scale=1">

\section{CONCLUSÃO}

No presente artigo foram discutidas as principais técnicas para desenvolver sites adaptáveis a qualquer tamanho de tela, utilizando recursos já existentes no CSS3. Notamos que não é simples desenvolver ou adaptar um site para ser responsivo, pois requer mais linhas de código e alguns cálculos e análises para trabalhar com layouts fluidos. Mas de fato é recompensador preparar o site para a atual/futura arquitetura da web responsiva.

Portanto, conhecer a tríade (layout fluídos, media queries e imagens responsivas) para construção de um site responsivo é importante para os web designs, sendo que se aprofundar mais neste assunto contribuirá no desenvolvimento de um site responsivo mais estruturado, seguro e expansível.

Os smartphones modernos pós-iPhone nasceram com um dilema: têm uma telarelativamente pequena, mas um navegador incrível capaz de renderizar todo tipo depágina, tanto as otimizadas para dispositivos móveis quanto as feitas pra Desktop. 


\section{REFERÊNCIAS}

LOPES, Sérgio. A web mobile: programepara um mundo de muitos dispositivos. São Paulo: Casa do Código, 2013.

MARCOTTE, Ethan. Responsive Web Desing. New York: A Book Apart, 2011.

MEYER, Eric A. Smashing CSS: técnicas profissionais para um layout moderno. Porto Alegre: Bookman, 2011.

ZEMEL, Tárcio. Web Design Responsivo: páginas adaptáveis para todos os dispositivos. São Paulo: Casa do Código, 2013.

WROBLEWSKI, Luke. Mobile First. New York: A Book Apart, 2011. 
